\title{
CONTEXTUALIZAÇÃO DOS DESDOBRAMENTOS POLÍTICOS E ECONÔMICOS DA CORRUPÇÃO ENVOLVENDO A PETROBRÁS: VISÃO DOS ESTUDANTES DE ENSINO MÉDIO EM TRÊS RIOS/RJ
}

\author{
Mayara Alves Vagueira' ${ }^{1}$ Angélica de Oliveira Soares ${ }^{1}$, Aline Lourenço da Costa ${ }^{2}$, Fabiola de \\ Sampaio Rodrigues Grazinoli Garrido ${ }^{1}$ \\ 'Universidade Federal Rural do Rio de Janeiro - UFRRJ, Programa de Educação Tutorial Conexões de Saberes por uma \\ Formação Integradora e Cidadã, Três Rios, RJ. ${ }^{2}$ Universidade Federal de São Paulo - UNIFESP, Mestrado em Economia \\ e Desenvolvimento. ${ }^{3}$. E-mail: email: mayara_vagueira@hotmail.com
}

\section{RESUMO}

No ano de 2014, o Programa de Educação Tutorial - PET do Instituto de Três Rios assumiu o compromisso de inserir jovens do Ensino Médio de escolas da rede pública na realidade do ambiente universitário. Desta forma, vem realizando desde então o "Projeto Escola-Universidade" que tem como finalidade apresentar aos participantes as estruturas da Universidade, ao proporcionar visitas guiadas e atividades em grupos de trabalho que tratam de temas atuais e relevantes para a sociedade. O presente artigotem como objetivo discorrer sobre a atividade do Grupo de Discussão intitulado "Petrobras: Desdobramentos Políticos e Econômicos", tendo em vista os recentes acontecimentos na estatal, que envolveram pagamentos de propinas, financiamento de atividade ilícita e que culminaram em prejuízos à conjuntura econômica do País. Palavras-chave: Lava Jato, política, economia, escola

\section{CONTEXTUALIZATION OF POLITICAL AND ECONOMIC CONSEQUENCES OF CORRUPTION INVOLVING PETROBRAS: THETRÊS RIOS (RJ) HIGH SCHOOL STUDENTS PERCEPTION}

\begin{abstract}
In 2014, Educational Tutorial Program - PET - in Três Rios Institute faced up to introduce university for public school students. Since that, the project named University-School aims at presenting university structure and proposing working groups to discuss recent and relevant issues. This article presents the activity proposed for the "Petrobras: Political and Economic Consequences" group, in order to discuss recent problems that involved bribery payment, financing illicit activity that have damaged the country economic structure.
\end{abstract}

Keywords: Lava Jato, politics, economy, school 


\section{INTRODUÇÃO}

Considerada a maior empresa nacional e também um grande patrimônio, a Petrobras, criada em 1939, tem como missão: atuar na indústria de petróleo e gás de forma ética, segura e rentável, com responsabilidade social e ambiental, fornecendo produtos adequados às necessidades dos clientes e contribuindo para o desenvolvimento do Brasil e dos países onde atua. (PETROBRAS, 2015)

O anúncio da descoberta de jazidas de petróleo ao longo da costa brasileira, conhecidas como jazidas do pré-sal, em 2008 gerou grande atenção em relação à legislação e aos rumos da economia no contexto dessa exploração.Desencadeada em março de 2014, a operação Lava Jato, investiga um grande esquema de lavagem e desvio de dinheiro envolvendo o pagamento de propinas e o financiamento ilícito de atividade política. A Petrobras teria sido palco de pagamentos de grandes empreiteiras do país e compra de projetos de lei, além de ter financiado campanhas políticas. O esquema consistia em pagamento de propina em obras da estatal por parte de empreiteiras, cujo dinheiro abastecia o caixa de partidos.A partir dos trabalhos da Polícia Federal, do Ministério Público e do Juiz Federal Sérgio Moro, um processo que envolvia crimes em licitações, lavagem de dinheiro e corrupção praticada na Petrobrás voltou a atenção para o crime de corrupção de agentes políticos.

O quadro atual é uma busca por transparência. A empresa apresentou recentemente o prejuízo recorde de 36,9 bilhões de reais no quarto trimestre de 2015, o que, segundo especialistas, apontaria para consolidar a confiança na atual gestão da empresa.Segundo o jornal The New York Times, o escândalo pode ser considerado o maior caso de corrupção do País, e isso, transcende as esferas sociais, causando transtornos político-econômicos internacionais (CBN, 2015).Em 2014, o país se aprofunda na apuração de denúncias de irregularidades em contratos da Petrobrás, dando início a Comissão Parlamentar de Inquérito (CPI) mista do Senado e da Câmara CPI da Petrobrás.

Através do "Projeto Escola-Universidade" o Programa de Educação Tutorial Conexões de Saberes (MEC/Sesu) do Instituto de Três Rios da Universidade Federal Rural do Rio de Janeiro, apresentou aos alunos do ensino médio da rede pública de ensino as estruturas da Universidade e atividades em grupos de debate que tratam de temas atuais e relevantes para a sociedade. Esses temas pertencem ao cotidiano social e acadêmico, e devem provocar e estimular o posicionamento dos estudantes, afim de contribuir para o exercício crítico da cidadania.

O presente trabalho tem como objetivo discorrer sobre a atividade do Grupo de Trabalho intitulado "Petrobras: Desdobramentos Políticos e Econômicos", tendo em vista os atuais acontecimentos na estatal, que afetam todos os segmentos- sociedade, políticos e organizações -, bem como toda a conjuntura econômica do País.

\section{METODOLOGIA}

O trabalho realizado se caracteriza como uma pesquisa participativa e exploratória, pois integra os pesquisadores à comunidade externa e gera reflexões através de debates com os envolvidos.

Em um primeiro momento, os discentes do programa de educação tutorial buscaram informações em diferentes fontes, tais como: artigos científicos, jornais de ampla circulação, sites, vídeos e documentários. Essa análise durou cerca de sessenta dias e após foi realizada uma apresentação para o grupo PET com o objetivo de debater e acrescentar informações para a apresentação destinada aos alunos participantes do encontro do "Projeto Escola-Universidade".

Após o preparo da apresentação em slides as mediadoras do grupo de discussão prepararam uma dinâmica, uma encenação e alguns recortes de jornais para estimular uma roda de conversa. 


\begin{tabular}{|l|l|l|}
\hline Grupo & $\begin{array}{l}\text { Mediadoras- O debate foi mediado } \\
\text { pordiscentes do PET pertencentes } \\
\text { aos cursos de Administração, } \\
\text { Economia e Gestão Ambiental. }\end{array}$ & $\begin{array}{l}\text { Participantes- Participaram do Grupo } \\
\text { de Discussão - GD, oito alunos do } \\
\text { Ensino Médio, entre o segundo e o } \\
\text { terceiro ano, sendo quatro meninas e } \\
\text { quatro meninos, com faixa etária } \\
\text { entre 16 e 17 anos. }\end{array}$ \\
\hline Material & $\begin{array}{l}\text { Foram utilizados como instrumento de exposição e discussão, slides, } \\
\text { matérias de jornais e um vídeo que contextualizam a estatal e o escândalo. } \\
\text { Como apoio para os participantes desenvolverem a dinâmica, foram usados } \\
\text { papeis A4, canetas e as matérias dos jornais pesquisados. }\end{array}$ \\
\hline $\begin{array}{l}\text { Procedimentos e } \\
\text { considerações da } \\
\text { atividade }\end{array}$ & $\begin{array}{l}\text { A atividade ocorreu em sala de aula, onde formou-se um semicírculo. As } \\
\text { monitoras do GD iniciaram as atividades com uma breve encenação sobre } \\
\text { pequenas corrupções presentes no cotidiano. Em seguida, houve uma roda } \\
\text { de conversa e a apresentação dos slides e do vídeo explicativo, a dinâmica e } \\
\text { por fim, responderam ao questionário de avaliação do evento. }\end{array}$ \\
\hline
\end{tabular}

\section{RESULTADOS}

A atividade teve início com uma encenação, feita pelas três monitoras, abordando ações presentes no cotidiano e que são tratadas com aceitação, mas constituem episódios de corrupção. Assim, foram tratados o troco dado a mais no supermercado, cortar filas, comprar mercadorias piratas, falsificar carteirinha de estudante, assinar lista de chamada pelo colega, usar o wi-fi restrito através de aplicativos, entre outros.

Após a encenação, os alunos foram questionados se as ações ali expostas estariam presentes no dia-a-dia deles, e se são adequadas ou não. Com isso tentou-se trazê-los para dentro do problema, fazendo-os sentirem-se responsáveis por atos corriqueiros, mas que são tão errados quanto a corrupção pública. Quando questionados, apenas uma pessoa disse que se recebesse troco a mais devolveria, os demais consideraram falta de atenção de quem deu troco. Eles não se enxergaram como agentes da ação, logo não se viram na obrigação de devolver e ainda se consideraram sortudos. Em relação à aquisição de produtos piratas, todos disseram que compram ou já compraram. E sobre o aplicativo que libera a senha do wi-fi restrito, houve inclusive um jovem que pediu à monitora que o passasse o nome do aplicativo.

Em seguida, foi feita uma apresentação de slides, com a contextualização histórica da estatal, explicação sobre o que é o Estado e troca de informações através de diálogos com eles.

Dinâmica:Logo após foi aplicada uma dinâmica que teve como objetivo despertar nos alunos a empatia pelos diferentes setores pertencentes ao escândalo Lava-Jato, através de manchetes que abordavam os diferentes pontos de vista e impactos que abrangem a sociedade, empresários e políticos. A proposta foi separar os alunos em dois grupos: um representando a sociedade e os empresários e o outro os políticos; e cada grupo teve vinte minutos para dissertar sobre a defesa do seu segmento mostrando os possíveis entraves que a operação gerou.Ao término do tempo estipulado, as monitoras da atividade os surpreenderam solicitando que esses deixassem de apresentar, em um primeiro instante, suas dissertações e defendessem o lado oposto através da leitura e exposição oral dos argumentos do outro grupo.Ao inverter as folhas dos grupos, os políticos viraram sociedade e o grupo da sociedade defendeu os políticos. 
Em ambos os momentos os representantes de políticos usaram argumentos como: faz parte do capitalismo, se eu não fizer, outro faz. E ao assumirem a posição de sociedade cobraram uma postura correta dos políticos e apontaram soluções para problemas básicos e que são negligenciados por eles.

Neste momento, depois dos debates e exposições das opiniões as monitoras deixaram uma mensagem reflexiva por meio do vídeo da cantora Ana Carolina, denominado: Só de sacanagem, que traz a leitura do poema de mesmo nome, de Elisa Lucinda.

Concluiu-se a atividade com o preenchimento do questionário de satisfação que avaliou:

1. O evento como bom, regular ou ruim;

2. Os aspectos do evento como: a organização, o tema do Grupo de Discussão, dos monitores, da durabilidade do evento;

3. Com base na experiência, se a pessoa voltaria ao evento - sim, talvez ou não;

4. O que a pessoa mais gostou;

5. O que menos gostou;

6. E sugestões para aperfeiçoamento dos próximos eventos.

\section{DISCUSSÃO}

Durante a roda de conversa ficou explícito que ações corriqueiras como as mencionadas não são consideradas corruptas pelos escolares.

Percebeu-se, através das defesas e reações de ambos os grupos, que existe um paradigma que estigmatiza todos os políticos como corruptos e toda a sociedade é vítima desse comportamento. Através desta constatação, abordou-se a necessidade de cada segmento assumir suas atribuições e responsabilidades. Aos grupos de empresários, foi dito que estes são erradamente os agentes que financiam as campanhas políticas. A sociedade tem como ferramenta o seu voto e seu poder de escolha e precisa saber fazer uso destes e não se colocar como vítima da situação. Deve assumir seu papel de protagonista, adotando o controle e poder que possui perante as decisões e responsabilidades que lhe são atribuídas. Quanto aos políticos, permanece o preconceito em relação ao fato de todos serem corruptos.

Isto posto, um dos alunos indagou se as monitoras fossem políticas, que certamente se deixariam se corromper. E mais, disse também que a corrupção neste meio é inevitável.

\section{CONCLUSÃO}

O encontro possibilitou a troca de saberes e opiniões sobre o tema proposto - Petrobras: desdobramentos políticos e econômicos -, assim como mostrou ao grupo de debate a necessidade de inserir cada vez mais alunos do ensino médio no espaço universitário e também dialogar sobre assuntos da atualidade que os direcionem para uma sensibilização de seu papel social e que se habituem a assumir uma visão crítica e cidadã. O trabalho aponta para a necessidade de apropriação dos direitos e deveres,cumprindo-se o papel perante a sociedade.

\section{REFERÊNCIAS}

AGÊNCIA SENADO. Sarney: "royalties do pré-sal devem ser igualmente divididos". 2009,http://www12.senado.leg.br/noticias/materias/2009/11/24/sarney-royalties-do-pre-saldevem-ser-igualmente-divididos. Acessado em 23 de março de 2016

AGÊNCIA SENADO.CPI recebe explicações de Sérgio Moro sobre participação de políticos na Operação Lava Jato. 2014, http://www12.senado.leg.br/noticias/materias/2014/11/26/cpirecebe-explicacoes-de-sergio-moro-sobre-participacao-de-politicos-na-operacao-lava-jato.

Acessadoem 23 de março de 2016. 
Guedes, S. Pre-Salt: What Has Been Done So Far and What is Coming Ahead. The 2015 Offshore Technology Conference in Houston, USA, 5 de maio de 2015, em http://www.energypedia.com/news/brazil/new-163488, Acessado em 23 de março de 2016.

https://www.youtube.com/watch?v=cE1VuxpOshl

PETROBRÁS. Novo Poço em Libra Confirma Presença de Óleo de Boa Qualidade. 2016, Blog Fatos e Dados, http://www.petrobras.com.br/fatos-e-dados/novo-poco-em-libra-confirma-presenca-deoleo-de-boa-qualidade.htm, Acessado em 23 de março de 2016.

PETROBRAS. http://www.petrobras.com.br/pt/quem-somos/trajetoria/

CBN. http://cbn.globoradio.globo.com/editorias/internacional/2015/02/04/NEW-YORK-TIMESCLASSIFICA-ESCANDALO-DA-PETROBRAS-COMO-MAIOR-CASO-DE-CORRUPCAO-DO-BRA.htm

Vídeo: Só de sacanagem. https://www.youtube.com/watch?v=cE1VuxpOshl

Faltam referências do vídeo e colocar outras referências que estão espalhadas no texto. 
Anexo:

Questionário de Avaliação Pós Evento

1- Como você avalia esse evento?

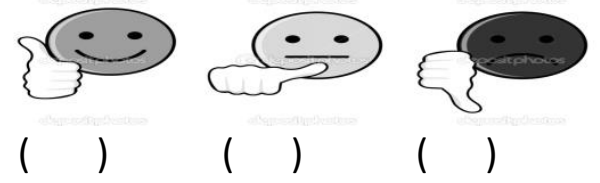

2 Por favor, avalie os seguintes aspectos do evento:

\begin{tabular}{|l|l|l|l|l|}
\hline & Excelente & Bom & Regular & Ruim \\
\hline $\begin{array}{l}\text { Organização } \\
\text { encontro do }\end{array}$ & & & & \\
\hline Lanche & & & & \\
\hline
\end{tabular}

3 - Com base na sua experiência com este evento, você voltaria?
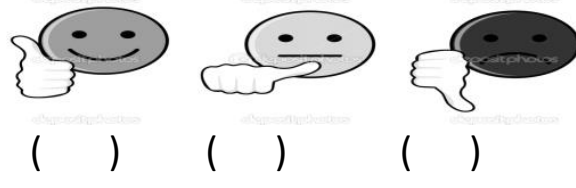

4 - O que você mais gostou?

5 - O que você menos gostou?

6 - Você tem alguma sugestão para nos ajudar a melhorar o evento futuro? 